\title{
Models of Citizenship and Civic Education
}

No man is an island entire of itself; every man is a piece of the continent, a part of the main; if a clod be washed away by the sea, Europe is the less, as well as if a promontory were, as well as any manner of thy friends or of thine own were; any man's death diminishes me, because I am involved in mankind. And therefore never send to know for whom the bell tolls; it tolls for thee.

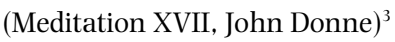

This well-known reflection by the seventeenth century English poet John Donne is a timeless expression of the idea we should feel solidarity not just with our immediate relatives, clan or nation, but with the whole human family. These ideas have a philosophical formulation in the idea of cosmopolitanism. Yet what is the basis of the idea that we should feel care for and responsibilities towards all human beings? Is it not right that our responsibility should be restricted to those closest to us, our family and friends or perhaps to our village, city or nation? These questions are central to discussions of ethics more broadly, but have come to the fore with the increasing prominence of debates around the concept of 'citizenship' in recent years. Citizenship has become a focal point for a variety of reasons, including the increasingly diverse nature of many formerly homogeneous societies through migration, debates over the granting of official residents' rights to undocumented workers, as well as disillusionment with the conventional political processes and institutions and the consequent decline in voter turnout in some countries.

Citizenship may be sought after by individuals and promoted by governments, but its meaning and associations are diverse and sometimes contradictory. First, there will be an initial sketch of the scope of the concept, followed by a consideration of the multiple possible interpretations.

\section{The concept of citizenship}

Citizenship is a form of membership, relating specifically to the political sphere. In the contemporary world, the political units in question are primarily nation-states, although the term can be traced back to the city states of the ancient world. Membership of a polity can be simply a question of official status, with citizenship in this sense associated with the possession of a passport and involving a formal set of rights and duties. Yet citizenship can also involve, in Osler and Starkey's (2005) terms, 'feeling' and 'practice'. In this sense, it is not so much a question of having the official status of citizen, but of how one conducts one's life - hence common conceptions of 'being a good citizen'.

Citizenship is commonly identified with democratic citizenship, and while it is possible to be a

3 This is a modernised rendition of the original seventeenth century prose. 
citizen of a non-democratic state, the concept indicates limitation of arbitrary power on the part of rulers, given that inherent in it is acknowledgement of the equality of all people (at least in some aspects) and some rights accorded to them. Within this skeletal definition, there are multiple conceptualisations of the notion, relating to diverse moral and political values. Citizenship involves a relationship between the citizen and other citizens or the state, and involves concessions and privileges on both sides. We can therefore observe differences in both the nature and extent of the rights and duties of citizens.

\section{Rights and duties}

One well-known classification of rights is that provided by T. H. Marshall (1950), who observed the historical emergence in Britain of first civil, then political and finally social entitlements. Civil rights in this sense refer to aspects such as legal protections and free speech, political rights to voting and standing as a representative, and social rights to education, health and welfare. Of these, the final category is the most controversial, and in most countries they have been very imperfectly realised to date. There are 'maximal' and 'minimal' positions on the extent of rights accorded to citizens (McLaughlin, 1992), with socialists advocating very extensive rights including social ones, and at the other extreme libertarians advocating the protection only of property rights.

However, it is not only a question of the nature and extent of the rights accorded to citizens, but also of the balance between these and duties. Conservative views tend to emphasise duties - the most extreme of these being to die for one's country - and models of citizenship weighted towards duties were prevalent in previous periods of history in which the balance of power between rulers and the populace was more obviously weighted in favour of the former. In the contemporary world, there are widespread concerns about an overemphasis on rights, based on the idea that people have forgotten their obligations towards others and are only concerned with their own gain.

Both positions of emphasising the obligations that citizens have without according them fundamental rights, and the so-called 'rights culture' in which people are concerned only with what they can claim from others, are problematic in their different ways. Yet it may well be that this separation of rights and duties is something of a misconception. If we accept the notion of universal rights - i.e. rights that all human beings can hold equally and simultaneously (setting aside for a moment the question of whether this is within a limited polity or across the whole world) then there will always be obligations, those to uphold the rights of others. In this way, intrinsic to the notion of right is the notion of obligation. Understood in this way, the only notion required is that of human rights, with corresponding duties contained within them.

Positions based in a limited view of rights have been critiqued from a viewpoint sometimes termed 'civic republican', which emphasises the value of active political participation (Heater, 1999; Kymlicka, 2002). Inspired by the participatory democracy of ancient Athens (although acknowledging the limited distribution of the official status of citizenship in this historical period), civic republicanism sees political action not just as a citizen's right, but as a valuable and even essential part of life. These arguments for participatory democracy (e.g. Barber, 1984; Pateman, 1970) are highly significant given the very restricted participation that people have in practice in contemporary democracies, and the educational initiatives discussed in this report to a large extent are based on an aspiration to enhance participation in this way. 


\section{Other dimensions of citizenship}

As stated in Civil Paths to Peace, according to 'a traditional liberal ... understanding of societal membership':

The concept of citizenship is indifferent to group identity or identities - the idea of citizenship does not differentiate or discriminate between people with different identities, it looks at national belonging alone.

(Commonwealth Secretariat, 2007: 49-50)

The universalisation of citizenship alluded to in this passage had positive motivations and consequences in as far as it avoided restricting the rights of certain groups on the basis of their identity. Nevertheless, this aspect has been strongly criticised for its homogenisation of society, leading to a devaluing of differences held to be important, and a lack of attention to inequalities hidden behind universal entitlements. In this way, there has been extensive feminist critique of the notion of citizenship (e.g. Benhabib, 1996; Mouffe, 1992; Young, 1990; Yuval-Davis, 1997), as well as from other perspectives, and calls for an approach that both guarantees entitlements and allows space for relevant differences.

Other challenges to traditional conceptions of citizenship focus on the scope of the polity. In a descriptive sense, an exclusive focus on the nation-state has been challenged by the phenomenon of globalisation, and movements towards the supranational or transnational level, and down to the local. A number of nation-states whose borders were the result of disputes from colonial times have struggled to develop a viable national identity, and with the weakening of national sovereignty there has been a resurgence of local, ethnic or religious identification. A tragic manifestation of the fragility of the national space was the ethnic conflict that took place in Kenya after the disputed 2007 election, which led to the deaths of 1,500 people and the displacement of 350,000. Broader allegiances across national boundaries can take place on the basis of ethnic or religious identity via diasporas, or other forms of cultural identification.

At the same time, nationalist sentiment has in many cases increased in recent decades, either in association with the break-up of larger states (e.g. the Soviet Union, Yugoslavia) or as a reaction to the arrival of increasing numbers of migrants (Brock and Brighouse, 2005). Beck (2006) describes these as 'introverted forms of nationalism which oppose the 'invasion' of the global world by turning inwards', although potentially leading to 'aggressive intolerance which is capable of turning on anybody or anything’ (p.4, original emphasis).

However, the increasingly multicultural nature of metropolitan centres is also an opportunity for the creation of a less parochial conception of citizenship. Beck (2006) sees cosmopolitanism as an essential feature of a world that has been forcibly unified through developments in technology, communications and economic ties. Terrorism, war and the responses to war have all become borderless. And yet, the response must be 'cosmopolitan empathy', rather than the economic globalisation that is based on exploitation for personal advantage, or a recast and well disguised nationalism. He portrays the character of a Danish businessman met on an aeroplane $-\mathrm{a}$ 'world citizen' in the sense of moving freely between places and cultures, identifying with all and none, and yet who maintains parochial and xenophobic attitudes. This form of 'world citizen', one whose knowledge of other cultures and ability to move and communicate are used to further personal and national interests, is a dangerous 'twin brother' to a cosmopolitanism grounded in 
global justice and empathy with all peoples. The economic global citizen is frequently promoted by governments through education systems - often to the detriment of education for global justice.

There is therefore a normative dimension to the move to the global. In this sense, identification at a global level is not just a consequence of the overwhelming tide of globalisation, but a moral commitment. This ethical position has a very long history, based in the idea that human beings are fundamentally one and equal, and that our moral and political obligations are to all people, wherever they may have been born. Cosmopolitan perspectives can take a number of different forms. Brock and Brighouse (2005) make a distinction between 'weak' and 'strong' cosmopolitanism, the former requiring 'some extra national obligations' (original emphasis), while in the latter, 'there are no society-wide principles of distributive justice that are not also global principles' (p.3). As the authors point out, few cosmopolitans would defend a position of total impartiality to all peoples in the world, and most would accept that it is quite appropriate for our primary attention and responsibility to be to those close to us - family, friends and those in our local area. The point is that there is not a choice between total parochialism and total impartiality, and that it is possible to maintain a balance between local, national and global responsibility and action. There are, of course a range of positions to be taken on this continuum.

In accordance with cosmopolitan ideals, a number of educators, organisations and sometimes governments have proposed education for global citizenship (e.g. Davies, 2006; Marshall, 2007; Osler and Starkey, 2003). These initiatives encounter the obvious problem of the absence of a global state to which formal citizenship might correspond - and therefore relate to the 'feeling' and 'practice' elements of the Osler and Starkey (2005) scheme, rather than 'status'. When these initiatives are channelled through state education systems, there may be tensions with national interests, although theorists like Appiah (2006) are confident that different levels of identification (local, national, global) can be maintained simultaneously. In any event, while citizenship education might open the possibility of global allegiances and responsibilities, the current reality of the nation-state must be acknowledged, and educational interventions must also prepare students for this context.

\section{Nussbaum's three capacities}

One important theorist proposing a cosmopolitan view is the political philosopher Martha Nussbaum. In development studies, Nussbaum is best known for her contributions to the capabilities approach, along with Amartya Sen. This report, however, will draw primarily on the proposals for educational aims relating to citizenship. The most extensive formulation of these is found in the book Cultivating Humanity (1997), and relates primarily to a defence of the liberal curriculum in universities, although it can be applied to all forms of education.

In Cultivating Humanity, and elsewhere (e.g. 2002, 2010) Nussbaum proposes three overarching qualities: critical self-examination, world citizenship and the narrative imagination. The first is the ability to examine closely one's own assumptions and positions, and the arguments put forward by others, to be able to question and critique them, and put forward coherent responses. Philosophy courses are seen to be the ideal way of developing this form of criticality, although Socratic dialogue can be built into any subject. 'World citizenship' relates to the moral and political position advocated by the Cosmopolitans, but also entails particular forms of knowledge that enable one to function in an international environment. To this end, Nussbaum proposes devel- 
oping broad knowledge of different cultures and countries, including language learning. Lastly, there is a narrative imagination, referring to 'the ability to think what it might be like to be in the shoes of a person different from oneself, to be an intelligent reader of that person's story' (Nussbaum 1997: 10-11). Studying literature is particularly important in developing this quality, although all the arts and humanities have a role.

As stated above, Nussbaum's discussion in Cultivating Humanity relates to higher education, and specifically to the US context. For this reason, some of the specific recommendations for the curriculum are bounded by that context - for example, the 'culture wars' regarding the literary canon. Other aspects, such as the defence of a broad curriculum including arts and humanities, and resistance to a narrow technological focus, are relevant for all levels of education. One contemporary development of relevance here is the movement of government funding away from supporting arts, humanities and social sciences in UK higher education - a potential risk to the respect and understanding agenda that is being replicated in different ways around the world on account of current economic constraints.

The three qualities fit closely with the respect and understanding agenda. First, critical self-examination guards against the mindless bigotry that often underpins conflict, fuelled by prejudice developed through restrictive school curricula. Instead, a broad cosmopolitan vision is proposed, including a strong rooting in the learners' own community and culture, but also a knowledge of other traditions and places, and the ability to empathise and communicate with other peoples, and consequently respect and understand them. This agenda fits closely with the field of intercultural education (e.g. Gundara, 2000), which will be explored in empirical contexts in the later sections.

Developing these qualities in education is a significant challenge, both in terms of the emergence of appropriate pedagogies and the acceptance of the goals themselves. Nussbaum discusses the possible resistance to critical self-examination, given perceptions of 'disrespect' to deep-rooted traditions. As she states, 'it can seem insulting to demand an argument for some political belief they [parents] have long held and have taught their children' (p.18). However, beliefs and values that have been subjected to critical reflection are in fact stronger, and can be communicated to others in a way that is more conducive to an overlapping consensus. Criticality in this way underpins democracy, in that a capacity to reason is essential for entering into genuine dialogue with others and reflecting on courses of action.

The cosmopolitan and critical aspects of this framework will inevitably come into tension with the currents of parochialism/nationalism and conformism that have long characterised education systems - but this tension must be faced up to if we are to move towards respect and understanding. But how are these qualities, or indeed any form of citizenship, to be developed through education?

\section{Citizenship and education}

Education is related to citizenship in the first place since it is considered to be one of the fundamental rights of a citizen, enshrined in the Universal Declaration of Human Rights and subsequent international rights instruments, and in the national legislation of many countries. Yet there is another significant way in which the two are connected, in the sense of education as 
a means to citizenship. In this way, individuals need education in order to exercise citizenship effectively in its different forms. When citizenship is engaged with as an aim of education, it is very often in the sense outlined above of attempting to foster positive dispositions amongst young people who already have the official status of citizen. There are cases, however, in which education becomes a requirement for citizenship in the 'status' sense, as with the 'Life in the UK' test, in which prospective British citizens are obliged to respond correctly to questions about society, its institutions and customs.

It is also useful to conceptualise the relationship in terms of the three ways in which rights link in with education (rights to, within and through education). First, there is the right to education, involving not only the provision of school places, but also attention to the specific needs of individuals and groups in accessing those places (Tomasevski, 2006; McCowan, 2010). In this way, nomadic groups in north-east Kenya require mobile forms of education, and the rural Quechuaspeaking population of Bolivia requires mother tongue provision. Second, human rights must be upheld within the educational institution and experience, of particular importance here being the protection of children from physical and psychological abuse, and from sexual harassment, which in many countries also leads to a high risk of contracting HIV/AIDS (UNICEF/UNESCO, 2007; Unterhalter, 2003; Wilson, 2004). Third, through education, young people must develop the capacities both to exercise their rights effectively, and to defend them in the political sphere. Rights are made effective when people have knowledge of them, and the skills and commitment to hold duty bearers to account.

\section{Knowledge, skills and values}

Promoting citizenship through education involves developing particular knowledge, skills and values in students. So for example, we may see that democratic citizenship requires people to have knowledge of existing laws, electoral procedures as well as current affairs and political theory; skills of textual interpretation, public speaking and debate; and the values of tolerance, collective decision-making and public engagement. For different conceptions of citizenship, these attributes will be correspondingly different.

Yet how do we develop these qualities? The 'knowledge' element is the bedrock of traditional schooling, but can also be acquired through independent learning with books, the internet and other sources of information. Skills are distinct in that they require actual practice of the activity, rather than solely abstract understanding, and therefore some of these can be developed in a classroom context - e.g. analysis of texts, oral communication - and others, such as campaign organisation, cannot. Values are the most complex of the three, since it is hard to determine the extent to which these can actually be 'learnt', particularly after early childhood, and the means by which this might happen. Learners' values can be influenced by 'exhortation' (being encouraged or coerced by a teacher), 'exemplification' (following the example of the teacher's behaviour), or 'reflection' (clarifying one's own values and considering those of others). While there may be a place for all of these, and all serve important pedagogical roles, none is a certain or predictable method of developing values.

Even if it were possible to identify effective means of changing people's values through education, there is still a question mark over whether it is in fact desirable to do so, given the need to respect people's existing beliefs, and the uncertainties surrounding the values to be promoted. As a com- 
promise, we might settle for a form of 'overlapping consensus' (Rawls, 1993), through which we allow for a diversity of values among students, but promote certain common values allowing us to live harmoniously together and enable the human flourishing of all.

\section{Neutrality and bias}

'Adjectival educations', such as citizenship and associated areas like human rights, have been greeted with a good deal of resistance around the world, in part because they are seen to be 'politicised', and are therefore challenging the objectivity and impartiality believed to underpin a 'good' education. Certainly, it is essential for education to be open and guard against indoctrination. Yet this does not mean cleansing education of all political content. One of the contributions of the Brazilian educationist Paulo Freire was his insistence that education cannot be neutral:

There never is, nor has ever been, an educational practice in zero space-time - neutral in the sense of being committed only to preponderantly abstract, intangible ideas. To try to get people to believe that there is such a thing as this...is indisputably a political practice, whereby an effort is made to soften any possible rebelliousness on the part of those to whom injustice is being done. It is as political as the other practice, which does not conceal - in fact, which proclaims - its own political character.

(Freire, 1994: 65)

Education, therefore, will always have political implications, whether that is through touching on political topics in discussion, or by forming fundamental attitudes relating to social relations, hierarchies and so forth. However, the essentially political nature of education does not mean that we can dismiss worries of bias and indoctrination. In relation to this, Roberts (1999: 20) makes an important distinction between '(a) transmitting a political or moral view and (b) doing this in a dogmatic way'. While we can certainly not avoid the former, all efforts must be made to avoid the latter, and students should be allowed to form their own views in dialogue with the teacher and other students.

Within citizenship education, the treatment of controversial issues has been the subject of considerable debate (e.g. McLaughlin, 2003; QCA, 1998). This question is particularly salient in those contexts in the Commonwealth that are currently experiencing conflict or which have experienced it in the recent past. Controversial issues may involve interpretations of history, views on particular cultural practices or the policies of governments or supranational agencies. Addressing these issues in the classroom presents significant challenges to teachers, faced as they are with a juggling act between their own views, the views of the state or education authority and those of the students.

The report (QCA 1998) underpinning the introduction of Citizenship in the National Curriculum of England and Wales is useful in this respect. It distinguishes between three different approaches that teachers can take:

- 'neutral chairman': allowing the pupils to express their diverse views

- 'balanced': presenting alternative viewpoints to those already expressed

- 'stated commitment': making one's views explicit, but encouraging pupils to decide for themselves. 
Each of these approaches may be appropriate in different contexts. The stated commitment approach will usually be suitable for older learners, but for young children may serve to stifle expression of independent views. The balanced approach is a useful way of promoting understanding of views that may be marginalised in a particular context, but would clearly be inappropriate in the case of certain issues (for example, in presenting an argument in favour of ethnic cleansing). A neutral chairman approach will often be the best way of allowing students to express themselves and to understand each other's views, but may need more teacher intervention if a diversity of positions is not being expressed.

\section{Sites of citizen learning}

\section{Classrooms}

Citizenship education can occur in a number of different spaces. Classrooms are the most obvious of these, given the institutionalised nature of learning in the contemporary age. While it would be very dangerous to limit citizenship learning to the classroom environment, there are significant opportunities that schools and universities provide. First, formal lessons are an ideal space for acquiring relevant knowledge of society, relating to history, human geography, political institutions and current affairs. Important skills such as critical analysis of texts, writing position papers and public speaking can also be developed. Classrooms are also key to deliberation, the central feature of participatory democracy. Through debating real issues, or through simulations, students can develop their abilities to present their arguments and listen to those of others, engaging with others in the process of respectful dialogue. In the context of a multi-ethnic, multi-religious, coeducational school (along with other forms of diversity) this discussion will be a real experience of engagement across difference.

\section{The school as a whole}

However, it is clear that the development of citizenship must go beyond the four walls of the classroom. Empirical research (e.g. Morris and Cogan, 2001; McCowan, 2008) - as well as common sense - tells us that the promotion of democratic citizenship in the curriculum is unlikely to be successful if the broader environment of the school is unsupportive, or at worst contradictory to, those messages. In this way, the ethos of the school, along with its approach to curriculum and pedagogy must reflect the aims of democratic citizenship (Ghanem, 2004). As shown in research on the 'hidden curriculum', the procedures and the rituals of schools are imbued with political significance, and (although it is hard to provide convincing empirical evidence) are likely to influence student attitudes and behaviour. The most cogent account of the significance of educational practice for political development is that of Paulo Freire (1972; 1994), who argues that political empowerment must start with treating students as subjects and not objects of the learning process, and involve their active participation in the development of curriculum and organisation of educational activities.

In recent years there has been a burgeoning of activity - of both an academic and practical kind - in relation to participatory, democratic schools. These initiatives, current examples of which are outlined in the following section, involve the inclusion of students in decision-making (such as through student councils), the development of a safe and caring environment respecting the rights of students and teachers, and the development of learner-centred pedagogies. 


\section{The wider society}

Schools have an unpromising history in terms of democratic practice, and as argued by Davies (2005), in the present age are more likely to be net contributors to conflict than beacons of peace. The reality of violent, authoritarian schools, and the broader undemocratic education systems in which they are inserted, might tempt us to abandon formal education altogether as a site for the development of democracy and mutual understanding. Nevertheless, it would be unwise to ignore schools, given their centrality in contemporary society in the lives of children and young people, leaving us with the challenging task of transforming them rather than seeking alternative avenues.

Having said this, citizenship education should not be confined to schools and other educational institutions. In fact, there are strong arguments to suggest that development of capacities for political understanding and action can only be developed with at least some experience of participation outside the institution. Schools - and particularly universities in the form of 'service learning' (e.g. Annette, 2005; Boland, 2006) - sometimes provide opportunities for students to engage in volunteering activities in local communities. However, while these are valuable activities both for the students and the community, engagement in society should also involve specifically political activities (i.e. based in a conception of citizens' rights and justice, rather than charity). There are significant constraints on schools facilitating this kind of activity - given their understandable reluctance to be perceived as party political or engaging students in controversial or dangerous activities (Westheimer and Kahne, 2000) - but campaigns, letter writing, debates and even protests are highly important for young people in their development of understanding and skills.

\section{'Adjectival' educations}

Thus far, this report has relied on the term 'citizenship education'. However, there are a number of different names that can be given to this kind of work within and outside schools. Subjects commonly found on curricula around the world that have some relationship to respect and understanding include:

- Citizenship education

- Civic education

- Civics

- Education for global citizenship

- Political education

- Human rights education

- Peace education

- Life skills

- World studies

- Development education

- Global learning

- Education for sustainable development

- Environmental education

'Citizenship' and 'civic education' are largely synonymous, although the term 'civics' tends to be associated with more traditional approaches, focusing on knowledge of the constitution and political institutions. Some of these curricular areas have particular foci-such as human rights, peace 
or the environment - while others are promoting a particular political vision, such as that of global citizenship. Yet they share a number of common features, in that they aim to promote qualities seen to be essential for individuals and society, but ones that are not given sufficient attention in the general curriculum. Frequently, these adjectival educations jostle for space within an already crowded curriculum, and for the most part lose out to the so-called 'core' subjects of maths, science and first language.

The struggle over curricular space is strongly related to the question of assessment. One of the challenges of promoting citizenship - and associated areas - in the curriculum is that it tends to be given less importance by teachers and students if it is not formally assessed and does not carry weight in terms of grades and certification. There are cases in which citizenship does lead to formal qualifications (there is a GCSE award in the UK for example), but there are significant challenges in assessing the subject, particularly in relation to the experiential aspects.

This study will refer to a number of these curricular areas in the sections that follow, although given the constraints of space will not be able to do justice to all of them, with the focus principally on those relating to democratic participation and civic values.

\section{Curricular transposition}

As seen at the start of this section, there is a multiplicity of different conceptions of citizenship that may be promoted within schools, ranging from conformist nationalism to critical cosmopolitanism. The kinds of activities associated with citizenship education can also take a variety of forms, from lecturing to problem solving, community work and mock trials. Yet what is the link between these activities and the underlying conceptions of citizenship? Are there certain activities that logically follow from certain conceptions, or is it necessary to conduct empirical research to verify the associations? If we can identify effective activities, will they always produce the desired form of citizen?

These difficult questions motivated the development of the curricular transposition framework (McCowan, 2008; 2009). This framework aids understanding of the transitions that an educational initiative makes between its fundamental aims, its curricular programme, its implementation in practice and the effects on students. The movement between these four stages is shown in the graphic below:

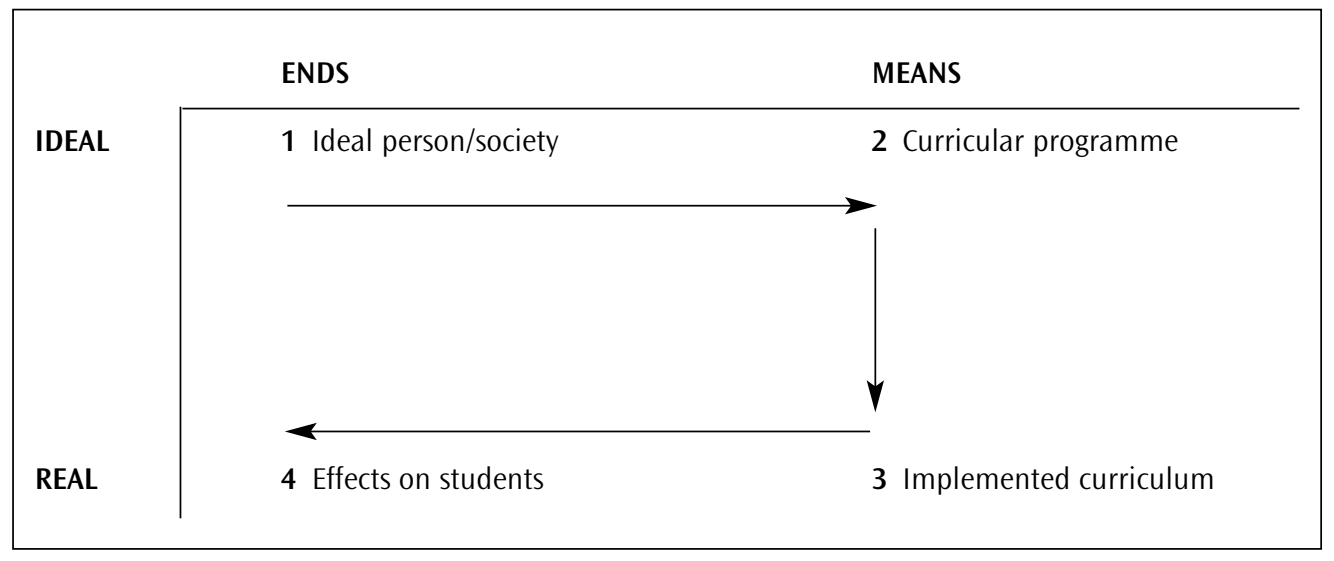


All initiatives are based on a set of ideals or aspirations, whether these are conscious and explicit or not. Some form of curricular programme is constructed in response to these ideals, and is then implemented in practice (although there may not be a straightforward linear chronology here). Between these different steps, there are likely to be inconsistencies and constraints, given the difficulties in developing coherent educational programmes and bringing them about in practice. Common obstacles in implementation include financial constraints, a restrictive political environment and teacher resistance or misunderstanding (although, as will be argued later, initiatives should not be implemented through teachers at all). Finally, there is the step of bringing about particular changes in students' attitudes and abilities, which is an unpredictable undertaking given the possibility of students interpreting and reframing the intervention in a number of ways. There are, therefore, challenges posed by each of these steps - here termed 'leaps'.

These 'leaps' are hard to negotiate for two reasons. First, in order to develop appropriate practice at a particular stage it is necessary to have considerable knowledge and understanding about teaching and learning, and information about the conditions under which it will take place. So, for example, there are always challenges faced by curriculum developers in identifying effective pedagogical practices, particularly so in an area as challenging as citizenship. Second, there are elements of uncertainty and unpredictability in all human activities, but particularly in educational interactions. In this way, learners may not absorb the messages transmitted through education, however clearly and effectively they are presented, or they may develop learning not originally intended. Far from being a problem, this can be seen to be the beauty of education - if indeed we are engaging in education and not a narrow form of mechanical training.

Thus far, this framework appears rather abstract, and divorced from the actual experience of teaching and learning citizenship. Yet it has an important practical function in highlighting key problems and misconceptions surrounding the promotion of citizenship through education, and indicating a particular way of moving forward. As outlined at the start of chapter 1, governments and other influential authorities often look to education as the saviour of society, laying at the school gates a particular set of goals to be delivered (stage one in the curricular transposition framework). However, achieving goals involving fundamental moral and political values is very difficult, particularly when those implementing and receiving the education have not been involved - and may not even endorse - the initiative in question. As will be seen in the case studies that follow, successful citizenship education requires a more organic development of educational work from the practices of teachers and learners: top-down or outside-in programmes are deeply flawed in this sense. 